\title{
Analysis of improved cleaning process targeting tough spot around the yogurt filling machine
}

\author{
Gu Yan ${ }^{1, a^{*}}$, Zhao Longtao ${ }^{2, b}$ \\ ${ }^{1}$ Food Engineering Department, Maanshan Teacher's College, Ma'anshan 243000, China \\ 2 Mengniu Dairy (Ma'anshan) Co., Ltd., Ma'anshan 243000, China
}

\begin{abstract}
The dairy industry produces sterilized room temperature yogurt. In the process of water flushing filling machine of valves $\mathrm{ABC}$ structure, the milk pressed by the seal ring of plunger valve A cannot be cleaned for a long time, causing scaling and increasing the risk of pollution. In order to avoid the risk, the filling machine need to be manually disassembled and cleaned which takes more than 4 hours, resulting in great loss of efficiency. This paper integrates the aseptic tank technology and filling technology of China Mengniu Dairy Company Limited. On this basis, the cleaning process of the sterile ${ }^{[1]}$ normal temperature yogurt filling machine is improved, the technology of water flushing valve A is innovated. It solves the problem of milk scale caused by the pressing of ring of valve A which is hard to clean, therefore minimizes the risk of microbial contamination. The improved process has been tested and applied to sterilized normal temperature yoghurt. The risk control of pollution products with high pectin fiber and even the filling machine with steam barrier structure in food industry is also applicable, which has certain promotion value.
\end{abstract}

\section{Brief introduction to valves $A B C$ of filling machine}

\subsection{Structure and function}

As shown in Figure 1, valve $\mathrm{A}$ is the switch responsible for the material liquid from the sterile tank to the filling ${ }^{[2]}$ machine. When valve A is opened, the sterile tank can feed the filling machine. When valve A is closed, the material liquid is cut off by valve $\mathrm{A}$, and the filling machine cannot function.

Valve B is designed for cleaning purposes, and valve A should be closed during cleaning process.

Valve $\mathrm{C}$ is a steam barrier setup when it is necessary to clean the sterile ${ }^{[3]}$ tank pipeline or filling machine pipeline separately on both sides of valve A, and the corresponding liquid can't be cleaned on the other side, in order to prevent the leakage of cleaning water caused by the leakage of valve $A$ to the other side to cause liquid and material pollution. In this case, there is steam ${ }^{[4]}$ in the steam barrier of valve $\mathrm{C}$, and the steam condensate is discharged to the ground through the steam trap, to ensure the condition is constantly high-temperature and aseptic ${ }^{[5]}$ between the sterile tank pipeline and the filling machine pipeline ${ }^{[6]}$.

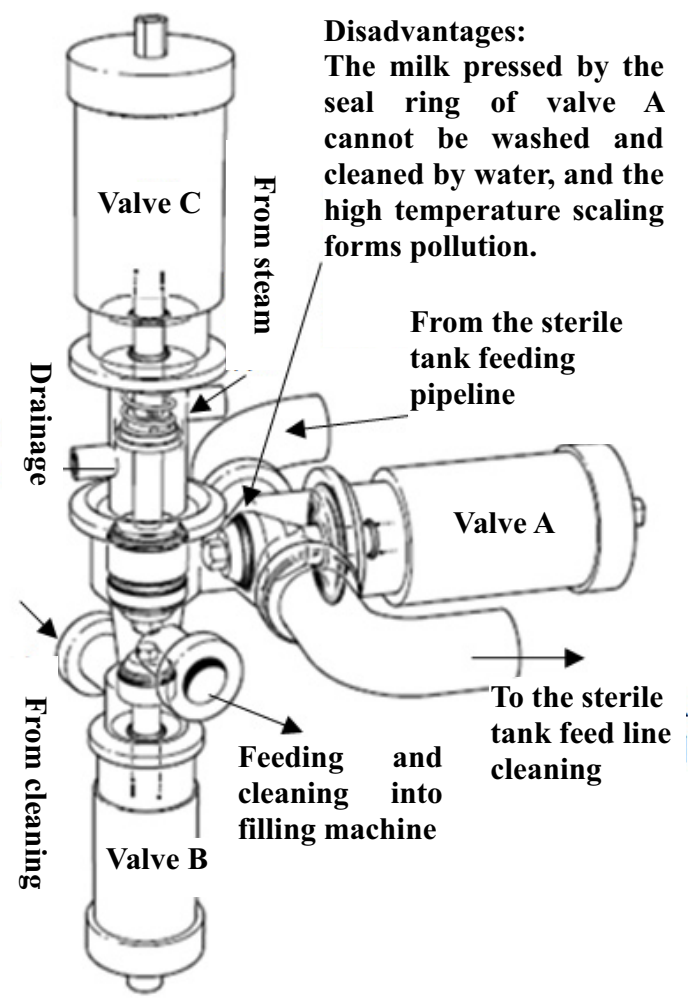

Fig. 1. Structure and function of water-jet valves $A B C$ on a filling machine.

\subsection{Disadvantages of valve $A$}

In the process of feeding production, valve $\mathrm{A}$ is closed, and the seal ring of valve $\mathrm{A}$ is pressed and closed during 
feeding production. Due to inherent design defects, milk pressed by the seal ring of valve A cannot be washed and cleaned for a long time, increasing the risk of pollution ${ }^{[7]}$. At the same time, the steam of valve $C$ heats ${ }^{[8]}$ the milk pressed by the seal ring of valve $\mathrm{A}$, which aggravates the possibility of pollution cause by scaling ${ }^{[9]}$.

\section{Background technology of filling machine}

Figure 2 demonstrates the section diagram of valves $A B C$ in the process of feeding. When valve A is opened, valve $\mathrm{C}$ will lift the steam to close, and the milk from the sterile tank pipeline will be fed to the filling machine for continuous production.

However, at the end of the production cycle shown in Figure 2, valve A is directly closed when the pipeline wall and valve seal are covered with milk, forming the part circled by the imaginary circle in Figure 3 below. A circle of milk pressed between the seal ring of valve $A$ and the pipeline wall cannot be washed and cleaned by any water.

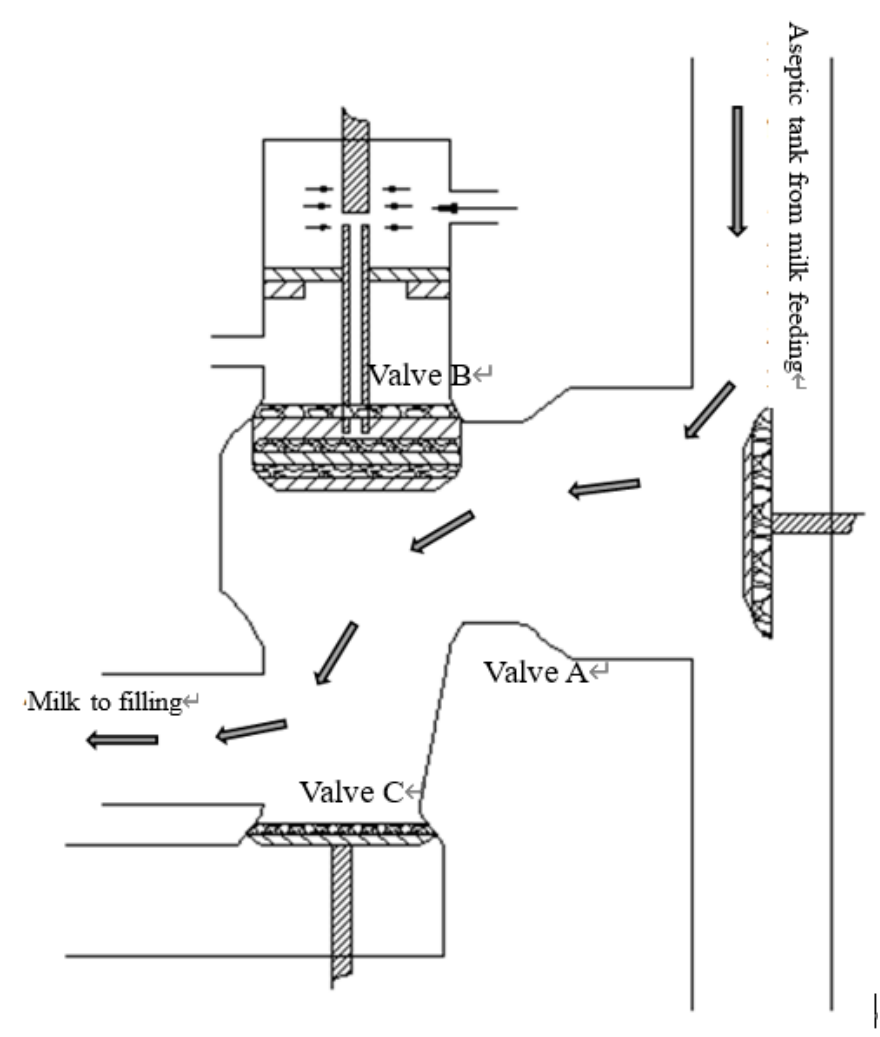

Fig. 2. Cross-section of valves $A B C$ in a feeding link.

In Figure 3, valve $\mathrm{B}$ is opened to make the cleaning fluid flow to the filling machine for cleaning.

If both sides of valve A need to be cleaned, valve $\mathrm{C}$ will be lifted to block the steam. If it is necessary to clean one side of valve $\mathrm{A}$, valve $\mathrm{C}$ will fall down, and the pipeline of valve $A$, valve $C$ and the filling machine will be cut off. At the same time, the steam will fill valve $C$ downward, forming a high temperature steam barrier between valve $\mathrm{A}$ and valve $\mathrm{C}$. At this time, the function of the steam barrier is to prevent the cross contamination between the cleaning fluid of the filling machine and the milk in the sterile tank pipeline when valve A leaks.

However, no matter whether valve $\mathrm{C}$ is lifted or sit at the bottom, valve A has an in-built disadvantage: A circular stain of milk scale pressed by the seal ring cannot be washed and cleaned by water, and long-term accumulation of the black milk scale causes pollution. Especially when there is steam barrier of valve $C$, the black milk scale will be further aggravated. The location of black milk scale is circled by dotted lines in Figure 3 below. 


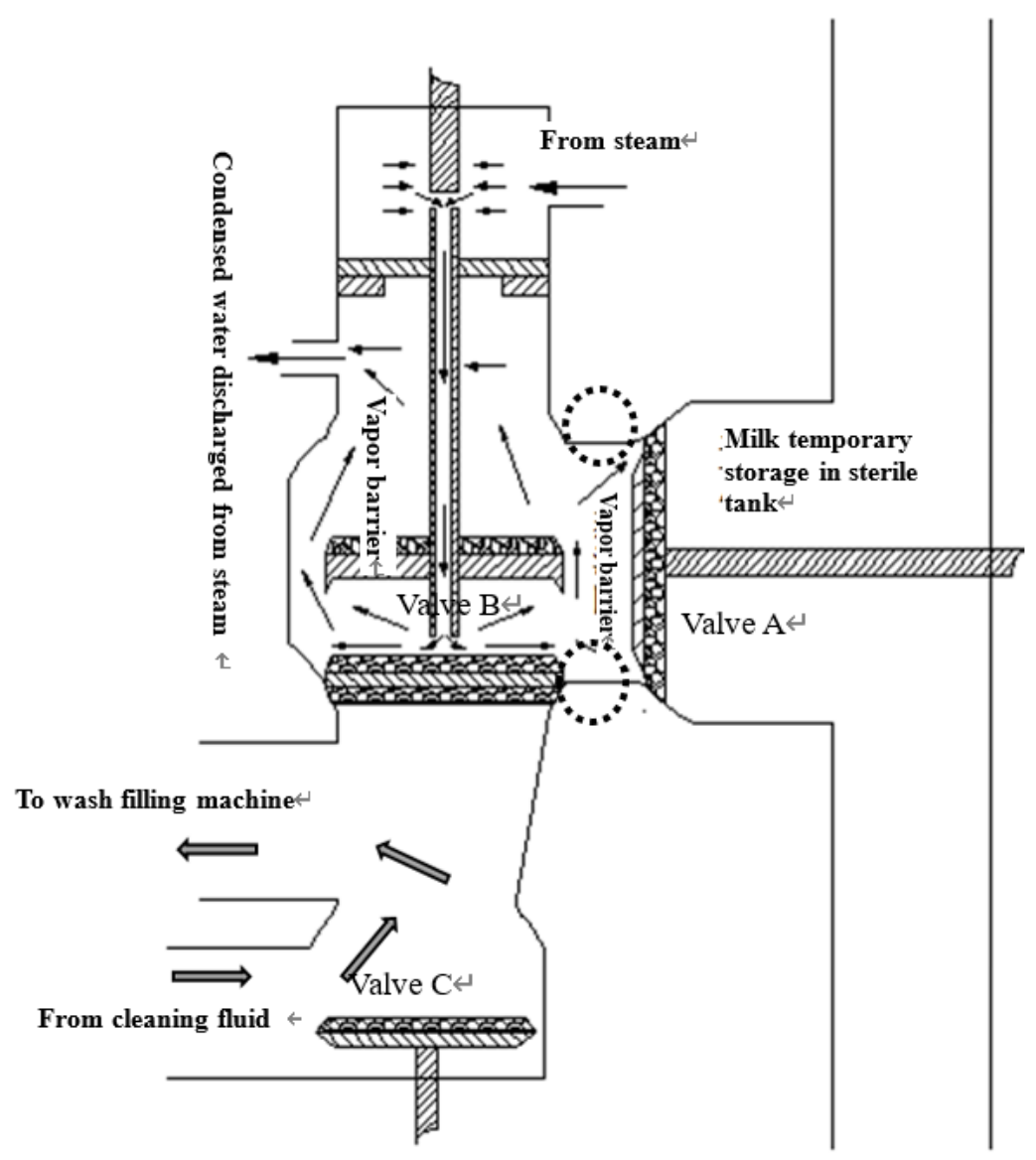

Fig. 3. Schematic of the cleaning process for valves $A B C$.

Figure 4 is an enlarged section view of the circled area from figure 3 . The cause of milk scale is that valve $\mathrm{A}$ is closed in all processes of water flushing and cleaning. The circular stain of milk pressed by the seal ring of valve A cannot be washed and cleaned by water for a long time. Under the high temperature of steam barrier and cleaning fluid $^{[10]}$, the milk quickly dries and forms scale. It is difficult to wash off the scale formed in this way even if it is removed for manual and mechanical force scrubbing.

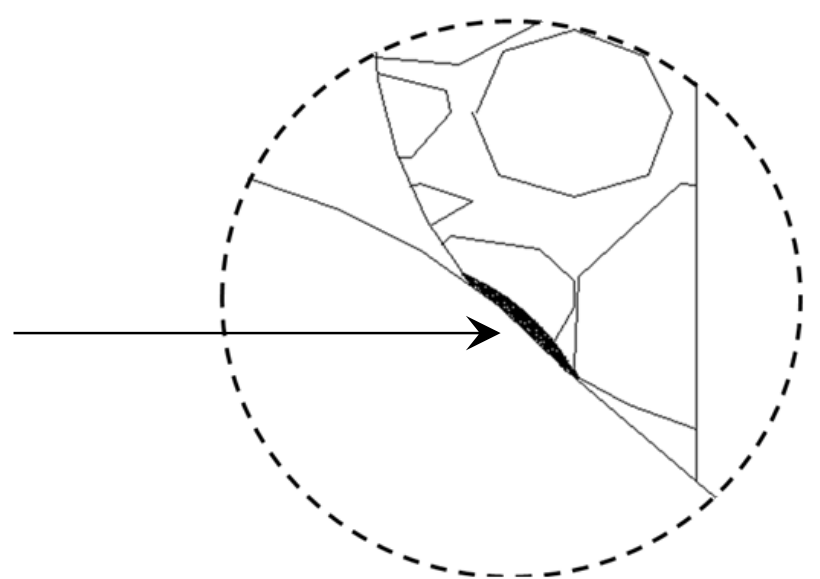

Fig. 4. Enlarged view of the location of black fouling under the seal ring of valve $\mathrm{A}$.

\section{Process improvement}

The gist of this process improvement is to change the streamline. The specific operation steps of the equipment are as follows:

Before improvement:

Step 1: water pushing milk. Push the milk from the sterile tank to the filling machine with water and fill it into finished products. When the milk mixture is about to be filled (the water pushing milk is about to end), valve $\mathrm{A}$ is closed, and the filling machine stops filling;

Step 2: water flushing the pipeline. After the filling machine stops, the water pipeline continues to pump water, but instead of going to valve $\mathrm{A}$, it goes to drain valve at the end of the sterile tank pipeline, in order to drain and flush the pipeline, and rinse until clean water appears at the drain valve at the end of sterile tank pipeline for more than 30 seconds;

Step 3: cleaning. After water flushing, clean the filling machine and aseptic tank on both sides of valve A.

The flow diagram before process improvement is as shown in Figure Group 5: 


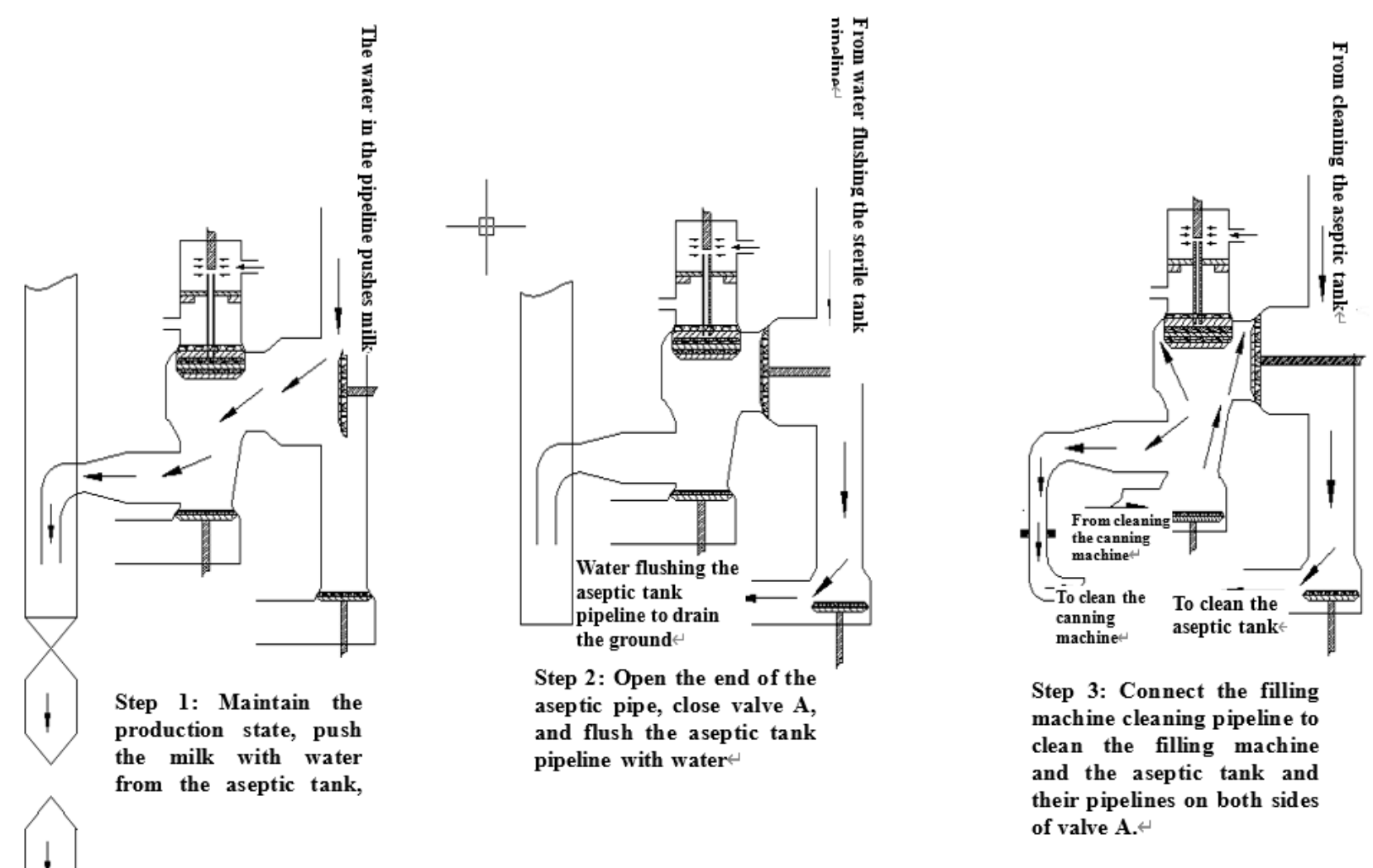

Fig. 5. Flow chart of the filling machine's cleaning process (Before improvement).

Implementation steps after process improvement:

Step 1: water pushing milk. Push the milk from the sterile tank to the filling machine with water and fill it into finished products. When the milk mixture is about to be filled (the water pushing milk is about to end), valve $A$ is closed, and the filling machine stops filling;

Step 2: water flushing the pipeline. After the filling machine stops, the water pipeline continues to pump water, but instead of going to valve $\mathrm{A}$, it goes to drain valve at the end of the sterile tank pipeline, in order to drain and flush $^{[11]}$ the pipeline, and rinse until clean water appears at the drain valve at the end of sterile tank pipeline for more than 30 seconds;

Step 3: Wait for the air to blow in the aseptic perfusion chamber to cool down, and reduce the temperature of the hot air in the paper tube to below $55^{\circ} \mathrm{C}$. After the cooling is completed, cut the paper tube of the filling head, and finally open valve $A$, so that the clean water in the pipeline in step 2 is flushed out through valve A to the drain head paper tube that has been cut, and rinse the wet milk pressed by the seal ring of valve A.

Step 4: Cleaning. After water flushing valve A with water, clean the filling machine and aseptic tank on both sides of valve $A$.

Figure 6 below demonstrates the simplified process after the implementation of the improvement.

In step 3, an additional procedure of separating the paper tube to cut is added. In step 4, the aseptic tank and cleaning, an additional tank is added. This procedure improvement completes cross-border integration between the aseptic tank technology and the filling technology. 

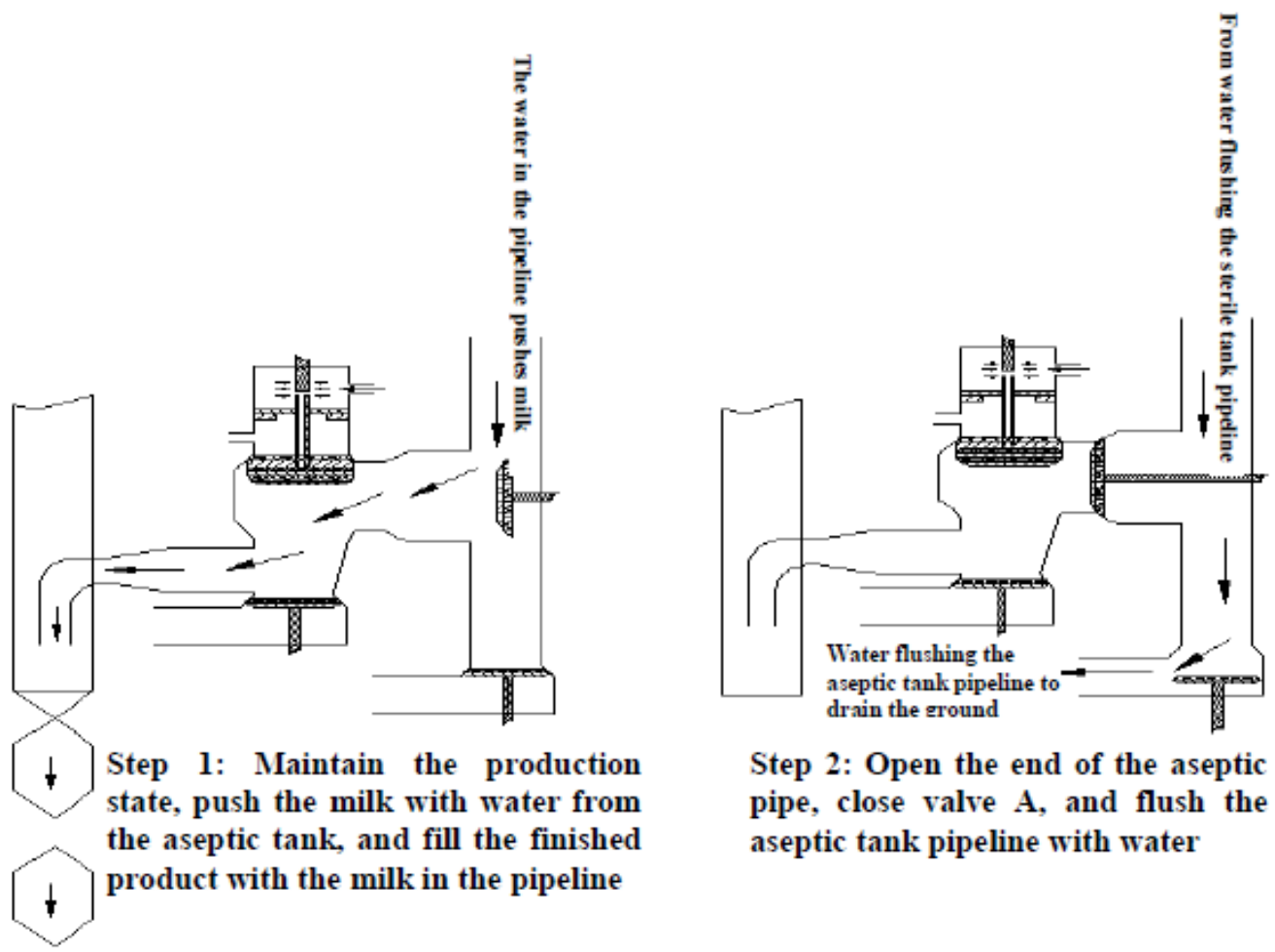

Step 2: Open the end of the aseptic pipe, close valve $A$, and flush the aseptic tank pipeline with water
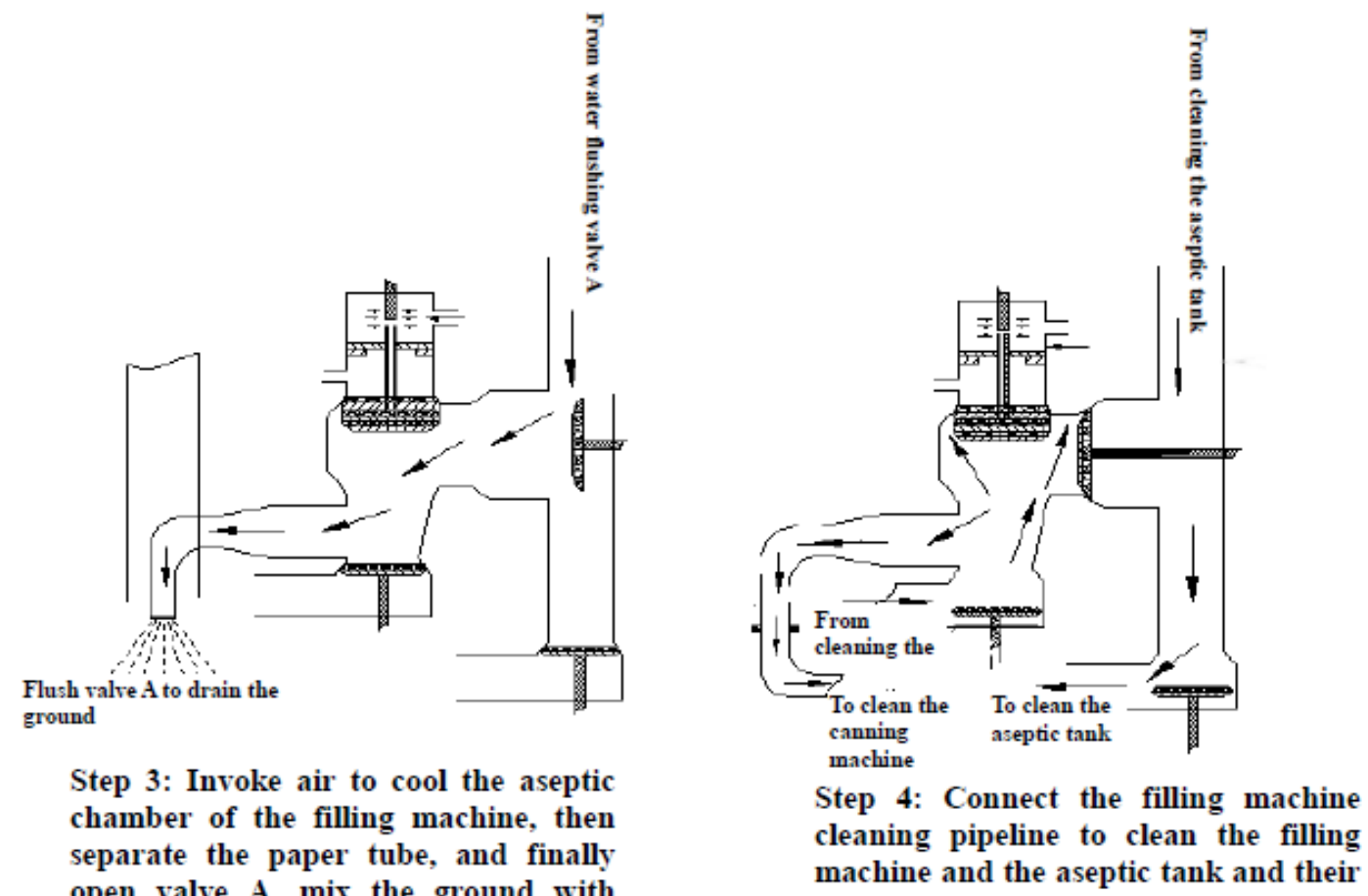

Step 3: Invoke air to cool the aseptic chamber of the filling machine, then separate the paper tube, and finally open valve $A$, mix the ground with clean water from the filling head, and rinse the moist milk pressed by the seal ring

Fig. 6. Flow chart of the filling machines's cleaning process (Improved).

\section{Key points of process improvement}

In addition, there are two points worth noting during this process:

1. After the end of sterile tank pipeline is drained completely for more than 30 seconds, it can enter the step of water flushing valve A. At the same time, water flushing valve A can be stopped only after the water flushing valve A to drain the ground is clear for more than 30 seconds.

2 . The pressure of water flushing valve A needs to be 0.4-1.9 bars, or the flow rate of water flushing is $4-8 \mathrm{t} / \mathrm{h}$. If it is too high, it will cause negative effects such as damage 
to the electronic components by the water splashed in the drainage part, while it will not be cleaned if it is too low.

After implementing this invention, the milk stain pressed by the seal ring of valve A will no longer cause scaling issues, therefore eliminated the risk of pollution, as shown in Figure 7.

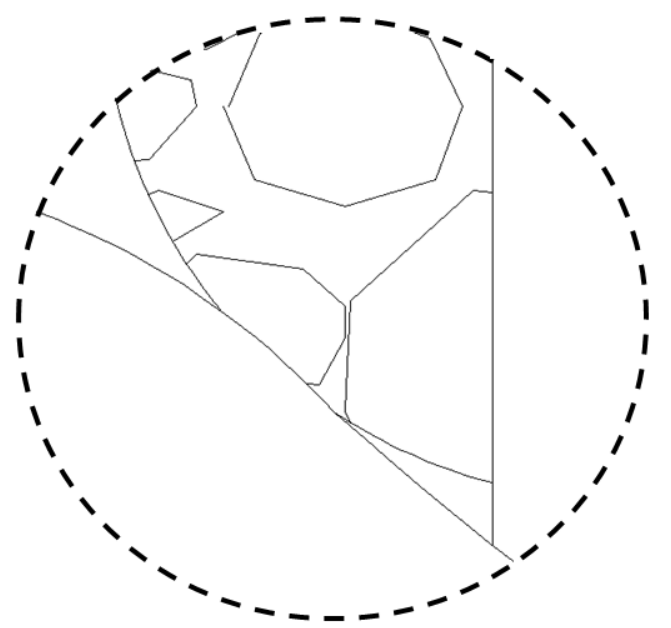

Fig. 7. Enlarged view of original black fouling location under the seal ring of valve A after process improvement.

\section{Conclusions}

In order to verify the effect before and after the process improvement, a test plan composed of two groups is developed, each with 20 samples. Ten samples are applied with ATP after water flushing, and ten samples are visually inspected for milk scale after CIP.

The pre-improvement approach is Sample Group 1:

Do not open valve A before water flushing, leave it for 3 hours after water flushing, disassemble the compressed part of the seal ring of valve A and apply ATP to collect 10 samples; do not open valve A before water flushing, leave it for 3 hours after water flushing for CIP, disassemble the compressed part of the seal ring of valve A to visually inspect the milk scale condition, and to collect 10 samples.

The post-improvement approach is Sample Group 2:

Open valve A before water flushing, leave it for 3 hours after water flushing, disassemble the compressed parts of the seal ring of valve A and apply ATP to collect 10 samples; open valve A before water flushing, leave it for 3 hours after water flushing for CIP, disassemble the compressed part of the seal ring of valve A to visually inspect the milk scale condition, and to collect 10 samples.

The results are as follows:

Table 1 Comparison of ATP content in seal ring of valve A before and after process improvement.

\begin{tabular}{|c|c|c|c|c|c|c|c|c|c|c|c|}
\hline $\begin{array}{l}\text { Sample } \\
\text { group }\end{array}$ & Sampling opportunity & \multicolumn{10}{|c|}{ Test results } \\
\hline \multirow{2}{*}{$\begin{array}{l}\text { Sample } \\
\text { Group } 1\end{array}$} & $\begin{array}{c}\text { Apply ATP after water } \\
\text { flushing without opening } \\
\text { valve A }\end{array}$ & 276 & 307 & 189 & 384 & 235 & 351 & 428 & 231 & 310 & 283 \\
\hline & $\begin{array}{c}\text { Inspect visually after } \\
\text { CIP without opening } \\
\text { valve A }\end{array}$ & $\begin{array}{l}\text { Small } \\
\text { amount } \\
\text { of milk } \\
\text { scale }\end{array}$ & $\begin{array}{l}\text { Slight } \\
\text { milk } \\
\text { scale }\end{array}$ & $\begin{array}{l}\text { Slight } \\
\text { milk } \\
\text { scale }\end{array}$ & $\begin{array}{l}\text { Slight } \\
\text { milk } \\
\text { scale }\end{array}$ & $\begin{array}{l}\text { Small } \\
\text { amount } \\
\text { of milk } \\
\text { scale }\end{array}$ & $\begin{array}{l}\text { Slight } \\
\text { milk } \\
\text { scale }\end{array}$ & $\begin{array}{l}\text { Slight } \\
\text { milk } \\
\text { scale }\end{array}$ & $\begin{array}{c}\text { Slight } \\
\text { milk scale }\end{array}$ & $\begin{array}{l}\text { Slight } \\
\text { milk } \\
\text { scale }\end{array}$ & $\begin{array}{l}\text { Slight } \\
\text { milk } \\
\text { scale }\end{array}$ \\
\hline \multirow{2}{*}{$\begin{array}{l}\text { Sample } \\
\text { Group } 2\end{array}$} & $\begin{array}{l}\text { Open valve A and apply } \\
\text { ATP after water flushing }\end{array}$ & 147 & 120 & 96 & 189 & 153 & 206 & 130 & 161 & 84 & 118 \\
\hline & $\begin{array}{c}\text { Open valve A and } \\
\text { inspect visually after } \\
\text { CIP }\end{array}$ & Clean & Clean & Clean & Clean & Clean & Clean & Clean & Clean & Clean & Clean \\
\hline
\end{tabular}

Description: The ATP fluorescence detector is based on the principle of firefly luminescence and uses the "luciferase-luciferin system" to quickly detect adenosine triphosphate (ATP). Since all living organisms contain a constant amount of ATP, the ATP content can clearly indicate the amount of microorganisms and other biological residues in the sample, which is used to determine the level of cleanliness.

The above two groups of sample data prove that the compressed part of the seal ring of valve A flushed according to the improved 4-step process can meet the requirements of the pre-water flushing step before CIP in the dairy industry: there is no visible milk scale on the surface of the equipment, and the cleanliness of the ATP application is obviously improved.

In addition, by implementing the improved process, each machine can save 8 hours spent on manual dismantling and washing to avoid pollution every week. Without the extra process of dismantling and washing, 200,000 more packages of products can be produced for the market every month. The increased gross profit and the reduced cost of dismantling and cleaning spare parts are nearly 50,000 yuan.

This improved process has been applied widely, and proven to be applicable to sterilized room-temperature yogurt. The risk control of product pollution with high pectin fiber and even the filling machine with steam barrier structure is also applicable, which has certain promotion value.

\section{Acknowlegedgements}

This work was supported by the Natural Science Research Project of Anhui provincial Education Department (NO. KJ2016A692); Anhui Quality Engineering Project in 2020 - School-Enterprise Cooperation Practical Education Base Project (NO.2020sjjd125).

\section{References}

1. Meng Hewei1, Kan Za1, Qi Jiangtao1, Xue Lingyang.(2016).Design and experiment on preparation and supply system of the pasteurized 
milk,25(4):267-275.

2. Wang Peiliang, Zou Shuhua.(2012). Improved CIP Cleaning Device of Roof Carton Filling Machine for Dairy Packaging: China, CN201120521782.5 [P]. August 1.

3. Cao Yongqiang, Yu Zhijian, etc.(2019). An In-Situ Cleaning System for Filling Machines: China, CN201811547899.3 [P]. March 1.

4. Cui Man. Research on the Filling Technology of BagIn-Box Liquid Flexible Packaging [D]. Wuxi: Jiangnan University, 2012.

5. Ren Heshan, Liu Yong.(2013). Analysis of Beer Factory Equipment and Related Cleaning and Disinfection Processes [J]. China Detergent Industry, September 28-31.

6. Scargiali, F., Busciglio, A., \& Caputo, G. (2013). Free-surface shape in unbaffled stirred vessels: experimental study via digital image analysis. Chemical Engineering Science, 104, 868-880.

7. Zhang Jiawei.(2016).Research on Food Safety Risk Management of Tetra Pak Liquid Dairy Project [D]. Beijing: Beijing Institute of Technology.

8. He Yifan, Zhou Jiejin, Liang Jianfen.(2019). Proteins and amino acids in bovine milk affected by heating conditions and storage duration. International Agricultural Engineering Journal,28(1):228-235.

9. Li Yaping, Zhao Wenwen,Jiangtao Qi1, Za Kan,Hewei Meng.(2020). Performance simulation and experiment of three-blade mixing device for normal milk processing[D].International Agricultural Engineering Journal,29(2):225-237.

10. Li, L., Yang, J., \& Xu, B. (2013). Numerical simulation of solid-liquid suspension characteristics for low-density particles in stirred vessel. Transactions of the Chinese Society of Agricultural Engineering, 29(16),42-49.

11. Ucar, T., Fox, R. D., Ozkan, H. E., \& Brazee, R. D. (2001). Simulation of jet agitation in sprayer tanks: comparison of predicted and measured water velocities. Transactions of the American Society of Agricultural Engineers, 44(2),223-230. 